East African Medical Journal Vol. 85 No. 4 April 2008

EFFECT OF HIV / AIDS ON HOUSEHOLD WELFARE IN UGANDA RURAL COMMUNITIES: A REVIEW

J. Nabyonga-Orem, MBChB, MSc, Health Economist, WHO Uganda Office, P.O. Box 24578, Kampala, Uganda, W. Bazeyo, MBChB, MPH, MPhil, Lecturer, Makerere University, Institute of Public Health, P.O. Box 22864, Kampala, Uganda, A. Okema, MA (Econ), P.O. Box 52802-00200, Nairobi, Kenya, H. Karamagi, MBChB, MSc, P.O. Box 45335, Nairobi, Kenya and O. Walker, MBBS, PhD, FMCP, FWACP, Clinical Pharmacologist, WHO Regional Office for Africa, P.O. Box 06, Brazzaville, Congo

Request for reprints to: Dr. J. Nabyonga-Orem, WHO Uganda Office, P.O. Box 24578, Kampala, Uganda

\title{
EFFECT OF HIV/AIDS ON HOUSEHOLD WELFARE IN UGANDA RURAL COMMUNITIES: A REVIEW
}

\author{
J. NABYONGA-OREM, W. BAZEYO, A. OKEMA, H. KARAMAGI and O. WALKER
}

\begin{abstract}
Objectives: To assess the impact of HIV/AIDS on household welfare. Explore the relationship between HIV/AIDS and poverty especially in relation to the Poverty Eradication Action Plan as well as make policy recommendations regarding action necessary to reverse or reduce the impact of HIV/AIDS on households (HHs).

Data sources: A cross-sectional study that utilised qualitative and quantitative research methods. Data were collected on the socio demographic profile; level of income; illness incidence and failure to work; loss of income due to illness; health expenditures for the last two months and modes of coping with health care costs.

Study selection: Study districts were selected based on regional representation and the HIV seroprevalence rates. The country is divided in four regions and the district with the highest seroprevalence in each region was selected.

Data extraction: Data was entered and analysed using EPINFO and proportions expressed as percentages.

Data synthesis: There were no children headed HHs among the controls and female and widowed HHs heads were more among the infected/affected HHs. The total average two months' expenditure on health care for control HHs was US $\$ 25$ compared to US $\$ 95$, for infected/affected HHs. Thirty two point two percent of $\mathrm{HH}$ heads who had missed work in the previous month gave illness as reason in the control group compared to $77.2 \%$ among infected/affected HHs. Fifty nine percent of these reported to have lost all their source of income as a result of the illness and $2.3 \%$ had salaries reduced. Twenty seven percent of the control HHs had children of school going age not attending school compared to $49 \%$ among the infected/affected HHs. Only $1.2 \%$ among the controls and $8.1 \%$ in the affected gave looking after the sick as reason. Methods of coping with cost of health care included sale of assets and withdrawing savings.

Conclusion: The study shows that HIV/AIDS impoverishes affected/infected households.
\end{abstract}

\section{INTRODUCTION}

Current estimates indicate that by the end of 2003 there were $1,200,000$ people living with HIV/ AIDS in Uganda and $83 \%$ of these were adults (1). AIDS is responsible for up to $12 \%$ of annual deaths and for the first time in 2001, it was the leading cause of death in adults (2). The prevalence and incidence of HIV has been declining significantly in Uganda because of government policies and interventions based on high-risk behaviour change (3). The worst affected age group are the $15-45$ years, which 
account for over $80 \%$ of the cases (4). As a result, HIV/AIDS touches every aspect of national life and development since these age groups belong to the cadre of pre-employment and labour force. There is therefore a big impact of the disease on the functions of the family, communities, the economy, care and support systems (4).

The Uganda government's response to the HIV/ AIDS pandemic is broad and predicates its strategy on the fact that the disease has serious negative impact on growth and development of the country and the economy. The Uganda national response to HIV / AIDS has therefore been characterised by a policy of openness about the epidemic, strong partnerships and community involvement backed by effective political and resource support from the highest level of Government. Thus, the thrust of Uganda's approach to mitigating against HIV/AIDS is based on a multisectoral and multidisciplinary approach with pooling of resources and expertise from all strata of the society. Although there are ongoing efforts to scale up of provision of free anti retrovirals (ARVs), currently (September 2007) only $46 \%$ of eligible population are accessing ARVs. This figure has remained fairly constant for the last four years (5).

In order to scale-up the national response to HIV/AIDS, a National Strategic Framework for HIV/AIDS was developed. One of the principal goals of this document is to mitigate the health and socio-economic effects of HIV/ AIDS at individual, household (HH) and community levels.

\section{JUSTIFICATION}

Previous studies done in Uganda on the economic impact of HIV/AIDS have concentrated on the impact of the disease at a macro and sectoral levels with limited efforts towards understanding the impact on the household. At present, there is insufficient evidence in Uganda to show the volume and gravity of the consequences of HIV / AIDS at the households. This deficit greatly hampers rational planning.

This study has therefore set out to bridge this gap in our knowledge of the subject. It is in keeping with the Multi-Sectoral AIDS Control Approach and the National Health Policy, whose strategies include mitigating against the negative impact of HIV / AIDS at the household level.

\section{POVERTY LINKS TO HIV/AIDS}

Studies that link HIV / AIDS and poverty have been done in the past. There is documented increased spending on treatment and burial expenses as a result of HIV/AIDS. Expenditures for lifetime care of AIDS patients in Burkina Faso were reported to be equivalent to twice the per capita income (6). In the Democratic Republic of Congo, the mean expenditures for an HIV-positive adult were nearly four times the monthly income (2). A survey done in Rakai district in Uganda showed that out of pocket medical expenditures for a terminally ill patient were more than double the average household income (7).

Productivity at individual levels decline because of inability to cultivate or report to work, and at household level, family members spend more time giving care to the sick, with less time for economic ventures. Thus some studies, have demonstrated a decline in production of cash crops as a result of HIV/AIDS $(1,8,9)$.

Other effects include reduction in contracting employment opportunities at individual level, and those who remain in employment face being placed on unpaid leave or having their working hours reduced or being paid in goods (paying medical expenses) rather than cash. In Gweru district, Zimbabwe, agricultural extension workers' attendance at funerals led to an average $10 \%$ loss of salary (10). In addition, most persons living with HIV/AIDS have been isolated, stigmatised and denied the needed care and psychosocial support (9).

In order to raise funds to meet HIV / AIDS illness related costs, some households diversify sources of income by undertaking a range of income generating activities such as selling fire wood, brewing local beer and selling livestock (10). In households where children are the caregivers, children as young as 10 years go out to work in an effort to get additional income to meet illness costs of a parent thus reducing opportunities for children education (10). In Malawi, 12-year-old girls were driven to have sex to fulfil short-term income needs (11). Studies done in Tanzania showed that households that did not have enough income to pay for health care, funeral expenses or education costs, sold assets in response to the crises $(7,12)$. The amount and type of assets disposed of vary across households. There 
is evidence to show that a wide variety of assets, except land, were disposed of to generate cash for use in seeking treatment. The range of assets most commonly sold included cattle, bicycles, chicken, furniture, carpentry tools, radios and wheelbarrows (11). Sale of agricultural produce has also been reported to be a dominant coping strategy to raise income to meet additional health costs, while some households pledged future crops to meet immediate cash needs $(7,9)$.

The informal financial sector including relatives, friends, neighbours, rural cooperatives, rotating and savings club associations, rural traders and moneylenders have been shown to be an important source of income during times of need (11). Relatives or friends may provide both moral and material support including meeting medical expenses for the patient. However, over time, the ability of these social networks to absorb these demands will decrease, as more adults die.

\section{STUDY OBJECTIVE}

The overall goal of the study was to assess the impact of HIV / AIDS on household welfare. It also set out to explore the relationship between HIV/AIDS and poverty especially in relation to the Poverty Eradication Action Plan (PEAP) as well as make policy recommendations regarding action necessary to reverse or reduce the impact of HIV/AIDS on households.

\section{MATERIALS AND METHODS}

Design: This was a cross-sectional study that utilised qualitative and quantitative methods of data collection. This survey employed structured interviews. The study took place between January and December 2002. The following data were collected from all HHs studied. Socio demographic profile; level of income; illness incidence and failure to work; loss of income due to illness; health expenditures for the last two months and modes of coping with health care costs.

Sample size estimation: According to Bennett et al, (13), a sample size of a minimum of 200 households per district is adequate. The formula takes into consideration the design effect to correct for the bias created when using cluster sampling in place of simple random sampling technique. With a design effect of 1.7, a selection of eight households per cluster/village, $95 \%$ confidence level and an estimate of the level of HIV/AIDs prevalence of $8 \%$ (14) in the general population, the calculation results into a minimum sample size of 600 households for each study population (cases and controls) for the four districts. A sample size of $310 \mathrm{HHs}$ was therefore selected for each district to make a total sample of $1239 \mathrm{HH}$ of which 602 were infected / affected HHs (cases) and $637 \mathrm{HHs}$ were controls.

Sampling: This was a multi-stage sampling procedure. At national level, the districts were divided into the four regions; namely Northern, Eastern, Central and Western regions. The district with the highest prevalence of HIV / AIDS in each region was selected using the prevalence figures published by AIDS Control Programme of the $\mathrm{MoH}$ (15).

Thus, western Kabalore, Central Masaka, Northern Apac and Eastern, Jinja districts were selected. Fifty percent of the sub-counties were selected randomly from each district. A sample of 25 parishes from the sub-counties was selected randomly using the probability proportionate to size technique from a sampling frame obtained from the 1991 census.

The technique involves a number of steps. In the first step, a list of parishes and their population sizes was drawn. At step two, the list was arranged in ascending order of their population sizes. In step three, columns showing cumulative totals of the parish population sizes were made. In the fourth step, a column showing the range of numbers associated with the corresponding parishes was constructed. From a table of random numbers, 25 numbers within the range of 1 and $N$, where $N$ is the district population size, were systematically selected. A parish was selected if a selected number fell within the range of numbers associated with it. Parishes with big population sizes had more chances of selection than those with small population sizes. If two random numbers fell within a range of numbers associated with one parish, then another random number was selected.

Selection of households: One Local Council (LC 1) at the lowest level (LC 1 is a village) was selected from a list of all LC 1s within the sampled parish by simple random sampling. $\mathrm{HH}$ identification was performed at the LC 1 level. An LCI has on average 70 HHs. Each LC 1 has Village Health Teams (VHT) 
comprised of seven people and each VHT looks after 20 households on average. These compile a minimal data set on general health issues for each household including, $\mathrm{HH}$ size, number of children under five and their immunisation status, sanitation, presence of a pregnant woman, presence of someone with a chronic disease and the nature and; deaths. This data is shared with LC 1 executive which is headed by a chairman and, the nearby health centre. These records are available with the LC 1 chairman. The Local Council (LC) chairmen identified all the infected and affected households in the community. This was cross-checked with the data held by HIV / AIDS home care programmes, who are health professionals, who carry out activities in the village and, by directly asking the people in the HHs. There was concurrence in all cases. In order to minimise hidden cases, selection was based on HIV/AIDS infected (where there was a sick person (due to AIDS) in the $\mathrm{HH}$ ) and affected $\mathrm{HH}$ (where a $\mathrm{HH}$ had lost someone due to AIDS) as opposed to an HIV infected person who may not have any signs of the disease. The study looked at an HIV/AIDS infected/affected $\mathrm{HH}$ referring to a $\mathrm{HH}$ having a person sick with HIV / AIDS or having lost a person due to HIV / AIDS and not necessarily the HH head. The process of selecting the first household to be studied begun at a central location within the LC1 (either at a bar, shop or cross-road). The direction was randomly determined by spinning a pen and every next identified $\mathrm{HH}$ was studied. For each $\mathrm{HIV}$ / AIDS infected/affected $\mathrm{HH}$ selected, a $\mathrm{HH}$ in the neighbourhood with comparable socio economic category was selected as a control. HHs included the infected/affected with HIV/AIDS and the control group (HHs that have never been affected). The findings from the affected $\mathrm{HHs}$ are compared with those from the control group.

Study population: The study population comprised of the adults/heads of households and the actual PLA if they were able to answer. Households included the infected/affected with HIV/AIDS and the control group.

HHs agreed to participate except where an adult was not available to answer the questions, but this accounted for a very small percentage $4 \%$ and $7.2 \%$ in the infected/affected and control HHs respectively where the $\mathrm{HH}$ head was a child.
Data management and analysis: The questionnaire was pre-tested in a district where the study was not to be conducted to ensure content and measurement validity. This was also to allow us make necessary modifications where required, before the study commenced.

All the completed questionnaires were edited to check for completeness and inconsistencies in the field. The data was entered using EPINFO version $6.04 \mathrm{~b}$ computer package, having screens with consistency and logical checks, made and tested. Analysis of the data was made using EPINFO version $6.04 \mathrm{~b}$, SPSS version 9.0 and MS-Excel packages. An analysis plan was made and executed to achieve the objectives of the study.

Ethical issues: Clearance to undertake the study was obtained from the Makerere University School of Public Health; institutional review board. Qualified personnel carried out this study. Subjects who met the eligibility criteria were requested to participate in the study after being given all the necessary information. The study team tried to answer any questions the respondents posed. Information obtained from the subjects during the study has been classified as privileged information and has not been divulged to anyone. Only aggregate information without subject identifiers has been published.

\section{RESULTS}

Health care seeking behaviour: The study showed that HHs use public health facilities more than any other health care option for both infected/affected $\mathrm{HHs}$ and control HHs (Figures 3 and 4). The use of traditional health practitioners was reported by $23.3 \%$ among the infected/affected $\mathrm{HHs}$ as compared to $0.8 \%$ among the control HHs.

A total of $1239 \mathrm{HHs}$ were studied of which $49 \%$ had a person living with HIV/AIDS or had lost a person due to AIDS and $51 \%$ were controls (had never experienced any HIV / AIDS illness) (Table 1). Details of the demographic characteristics of the studied HHs are shown in Table 2. Notably; there were no children headed HHs among the controls and female headed and widowed $\mathrm{HH}$ heads were more among the infected/affected HHs. Average household size among the infected / affected HHs was 6.71 (S.D=3.47) compared to an average size of 6.05 (S.D=3.15) among 
controls. This is higher than the average $\mathrm{HH}$ size documented in the Uganda Demographic and Health Survey (UDHS) of 4.8 .

In order to document the impact of HIV/AIDS on the affected HHs, the direct and indirect costs incurred by HHs while there is a patient in the home were estimated and coping mechanisms were studied. For the control group, $\mathrm{HH}$ expenditure on health care was obtained.

Average household health expenditure: In order to avoid recall bias, the previous two months were used to estimate the household health expenditure. The total average two months' expenditure on health care for control HHs was US\$25 compared to US $\$ 95$, for infected/affected HHs. Figure 1 shows that hospitalisation and HIV/AIDS related surgical intervention were the most expensive health care costs for the affected/infected HHs with an average two months' expenditure of US $\$ 25$ and US $\$ 22$ respectively, while the highest expenditure for the control HHs was on hospitalisation followed by pharmaceuticals at US $\$ 10$ and US $\$ 8$ respectively (Figure 2).

Table 1

Number of households studied

\begin{tabular}{lcccc}
\hline District & \multicolumn{2}{c}{ Infected/affected (cases) HHs } & \multicolumn{2}{c}{ Control HHs } \\
& Frequency $(\mathrm{HH})$ & $(\%)$ & Frequency & $(\%)$ \\
\hline Apac & 157 & 26.1 & 160 & 25.1 \\
Jinja & 145 & 24.1 & 161 & 25.3 \\
Masaka & 148 & 24.6 & 166 & 26.1 \\
Kabarole & 152 & 25.2 & 150 & 23.5 \\
\hline Total & 602 & 100 & 637 & 100 \\
\hline
\end{tabular}

Table 2

Demographic characteristics of controls and affected/infected HHs

\begin{tabular}{lcc}
\hline & Infected / affected HHs (\%) & Control HHs (\%) \\
\hline Heads of HHs as respondents & 89.0 & 60.3 \\
Spouses as respondents & 7.0 & 32.5 \\
Male headed HHs & 52.0 & 75.8 \\
Female headed HHs & 48.0 & 24.2 \\
Children headed HHs & 4.0 & 0.0 \\
Married HH heads & 45.0 & 54.2 \\
Widowed & 40.0 & 14.5 \\
Single & 7.0 & 4.1 \\
Separated & 3.0 & 7.3 \\
Average HH size & 6.71 & 6.05 \\
Education level of head of HH & & \\
$\quad$ Never attended school & 18.0 & 17.5 \\
$\quad$ Primary education & 56.6 & 54.0 \\
High school & 21.8 & 23.3 \\
\hline
\end{tabular}




\section{Figure 1}

Two months' average $H H$ health expenditure among the affectedlaffected $H H s$

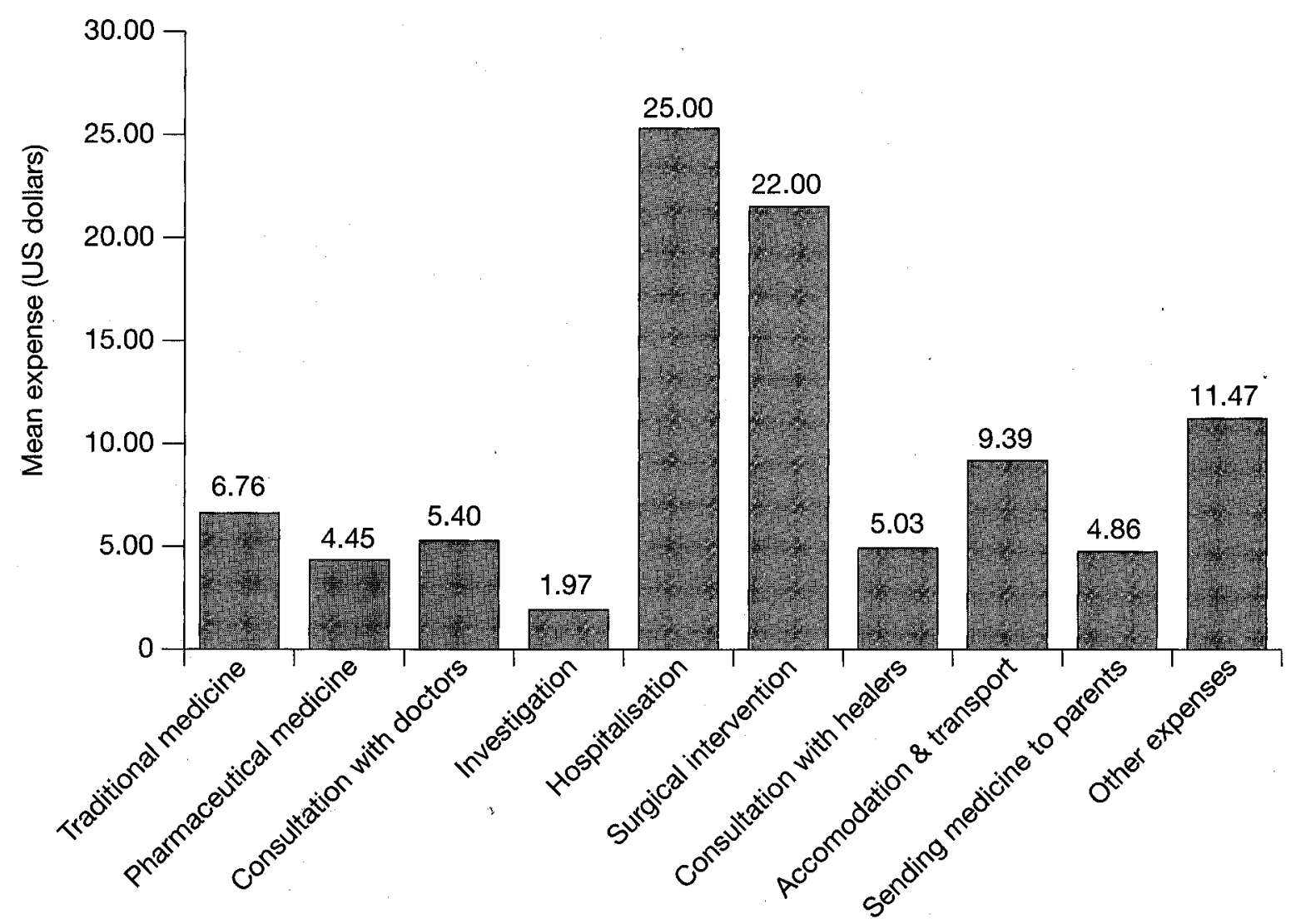

Figure 2

Average HH health expenditure for two months control

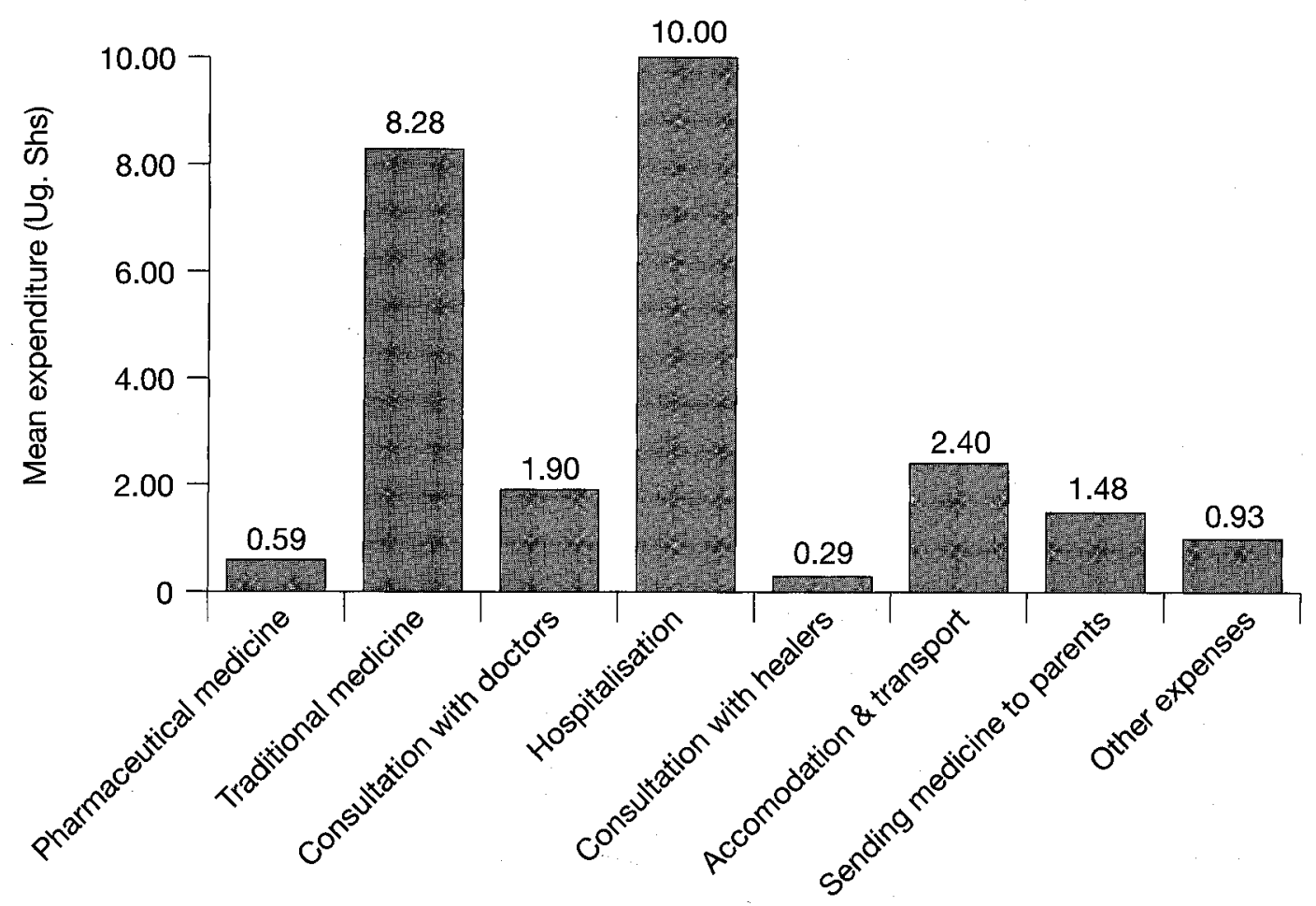


Figure 3

Health seeking behaviour among the affected/affected HHs

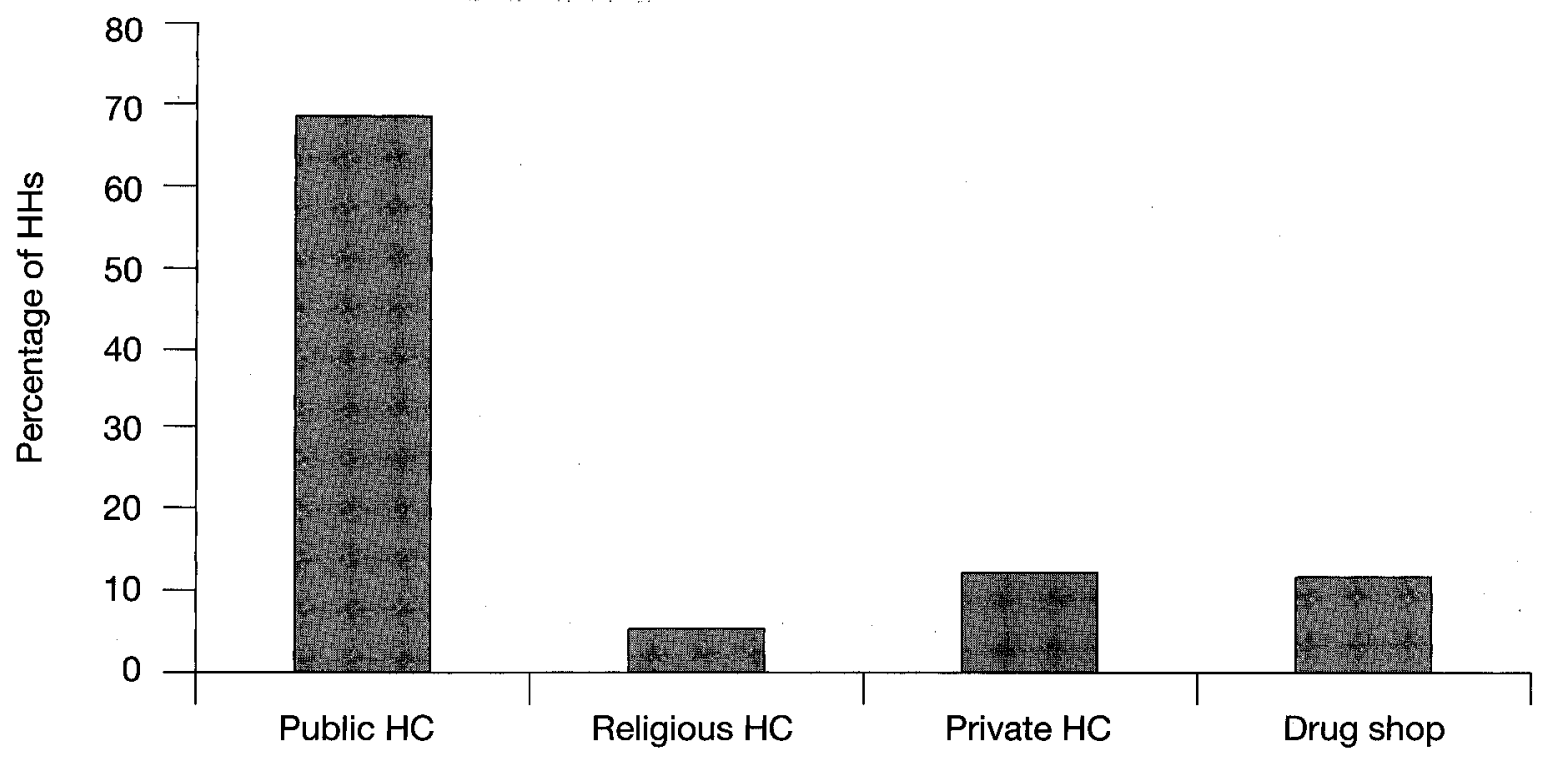

Figure 4

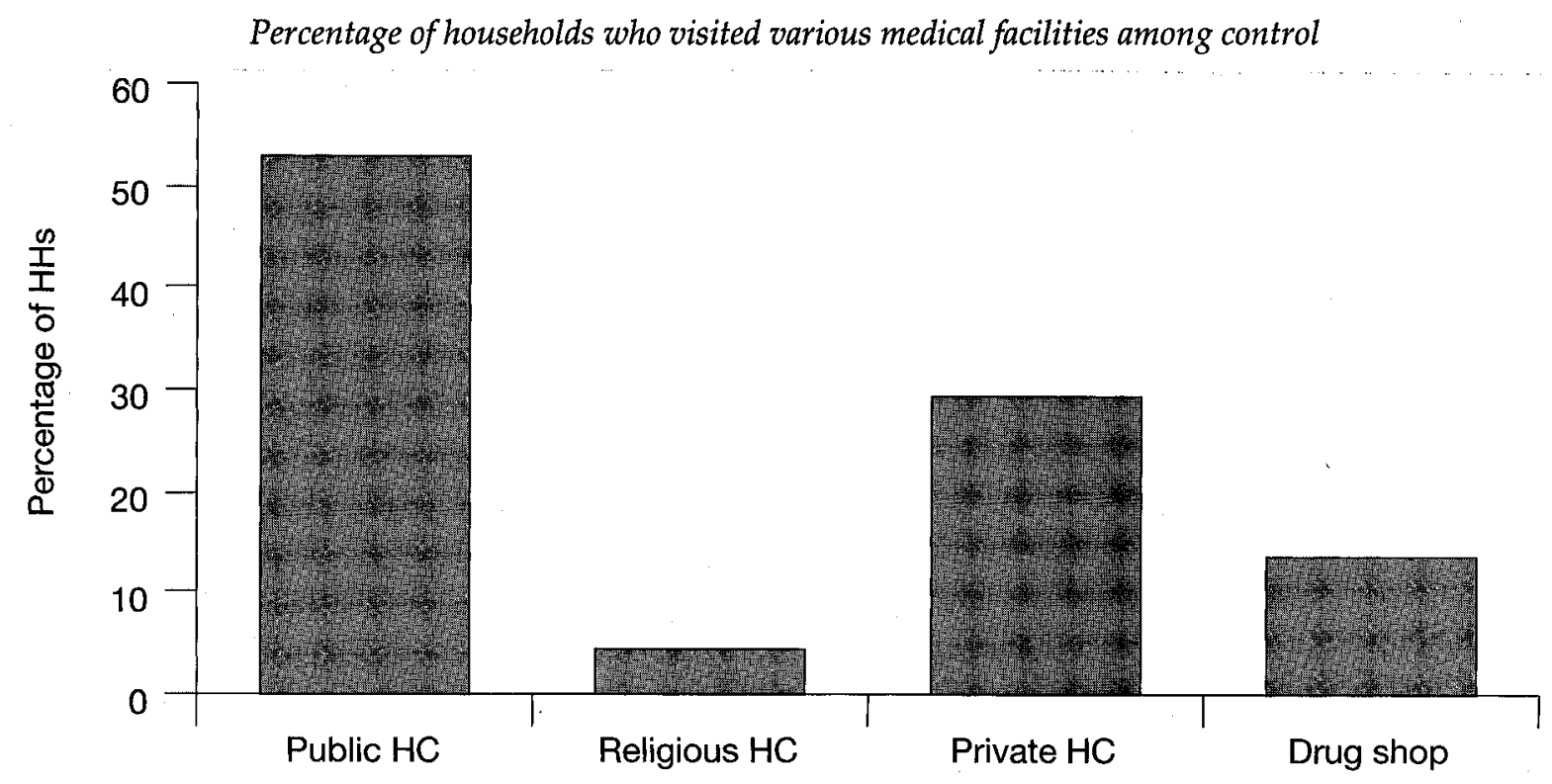

Health expenditure for the HIV/AIDS patients (for HHs where there was a patient) as a percentage of the head of the HH head's monthly income was also studied. Results showed that hospitalisation and HIV/AIDS related surgical interventions accounted for an average of $22 \%$ and $15 \%$ of the HH head's two months' income respectively. Seventy four percent of the infected / affected HHs interviewed lived in debt incurred due to expenditure on HIV/AIDS related costs. Traditional medicine and consultations with healers played a bigger role in the infected/affected group while in the control group formed the least health care expenditure. The pattern of expenditure on health care of the HIV/AIDS patients was reported to be increasing as each year passes and this could be attributed to the progression of the disease.

Indirect costs: It was noted that several heads of the HHs did not work in the last one month and on comparing them; the control $\mathrm{HHs}$ had $24.8 \%$ compared to $50.3 \%$ of the infected/affected HHs. 
To differentiate the reasons for not attending work, it was found that $32.2 \%$ of those who did not work gave illness as the main cause in the control group while the infected / affected group had $77.2 \%$ of them and of these; about $67.7 \%$ had missed for one month or more. Missing work was associated with loss of income and this was evident in $89.8 \%$ of those who missed work. Among these, 59\% reported to have lost all their source of income as a result of the illness and $2.3 \%$ had their salaries reduced. Therefore this big difference could be attributed to HIV/AIDS, which results into low incomes for the households with HIV / AIDS patients.

Twenty seven percent of the control HHs had children of school going age that were not attending school compared to the higher percentage of $49 \%$ among the infected/affected HHs. Several reasons were given for non-school attendance of the school age children and the commonest among both groups was lack of financial means. However, it had varying magnitudes as could be seen to have affected $64.2 \%$ of controls as compared to the $81.1 \%$ of the affected. It has been documented in several studies that children stay behind to look after sick people in their homes and that this forms one of the main reasons for not attending school among the affected households (16). In this comparative study only $1.2 \%$ were not attending school for this reason in the control group as compared to $8.1 \%$ in the affected group.

Coping mechanisms: The data on direct cost (expenditure) on health care of People Living with AIDS indicates that $87.4 \%$ of the respondents paid cash while the rest either depended on their savings, got loans or grants or sold their livestock, poultry, crops and land. Eighty percent reported withdrawing their saving to care for a household member. While $15.4 \%$ solicited aid from friends or family. Control HHs significantly reduced aid $(17.4 \%)$ to family or friends as one of the ways to cope with financial difficulties.

It was also noticed that the districts with higher health care costs had many HHs reporting having had incidence(s) of sickness. This is also associated with $\mathrm{HH}$ size as well as taking children out of school. Larger HHs were more likely to have problems in financing health care as well as paying for their children in school. Taking children out of school whether boy or girl was therefore associated with large families and large $\mathrm{HH}$ expenditures.
The study tried to enlist from the interviewees their perception towards the standard of living in the last couple of years. $46.2 \%$ and $85.3 \%$ of controls and infected / affected HHs reported decrease in standard of living respectively. Fifteen percent of control HHs reported an improvement in the standard of living while only $2.7 \%$ of the affected reported some improvement. The standard of living was however subjective to the respondents of this study much as efforts were made to qualify it.

\section{HIV/AIDS, Poverty and the National Poverty Eradication} Action Plan (PEAP): When asked to comment on the ability to meet basic needs, majority of infected/ affected households reported that they found it difficult to meet health care needs of both children and adults implying that poverty significantly affect $\mathrm{HH}$ ability to meet HIV/AIDS health care more than other needs. However, the inability to meet the health care of adults ( $81 \%$ of $\mathrm{HHs}$ ) was higher than that for children $(79 \%)$.

\section{DISCUSSION}

The study has shown how HIV / AIDS impoverishes $\mathrm{HHs}$ as a result of high health care expenditures, loss of jobs and income, loss of savings and assets and reduced standard of living. Expenditure on health care has been shown to be much lower for control HHs as opposed to infected/affected HHs. Thirteen percent of affected HHs reported use of savings, borrowing and sale of assets to cover medical expenses. Other impact studies have shown similar findings, in Rwanda, $18 \%$ of affected $\mathrm{HH}$ resorted to borrowing in order to finance health care expenses (17). In South Africa, (the Free State Province) $72 \%$ of the affected $\mathrm{HHs}$ borrowed money to cover health expenses as compared to only $25 \%$ of non-affected HHs (7). Studies done in South Africa have shown that AIDS deaths, which follow on AIDS morbidity, lead to a more permanent cut back in the labour supply of affected $\mathrm{HHs}$, decreasing the future earning potential of the $\mathrm{HH}(17,18)$. The impact of an AIDS death may, because of it's protracted nature, result in a lengthy depletion of $\mathrm{HH}$ resources thus resulting in greater and more enduring hardship than some other causes of death (19). Affected HHs are more likely to be trapped in a vicious cycle of the need for desperate health care and deepening poverty. 
Children are taken out of school to care for the sick or due to lack of school requirements and this was found to cut across all the regions studied. The impact of HIV on children's education affects future labour supply and income for $\mathrm{HHs}$ given that children are denied a chance to study because of financial problems and or caring for the sick. A survey done in Zimbabwe found that $31 \%$ of households interviewed had a child who was not attending school following the death of the mother (20). In Zambia focus group discussions with AIDS-affected HHs found that $55 \%$ were unable to meet the costs of their children's education as a result of AIDS (21).

In addition, a study done in Swaziland documented the decreased physical, emotional and mental welfare of a child following loss of one or both parents with negative consequences on the child's education $(1,21)$. This will result into reduced skilled labour in the future thus, higher training needs.

The impact of HIV/AIDS has been quantified by other impact studies in terms of difference in $\mathrm{HH}$ size, $\mathrm{HH}$ structure and dependency ratios that reflect changes in the composition of affected HHs. The dependency ratio in affected $\mathrm{HHs}$ was shown to be higher than in non-affected HHs and a larger proportion of these consisted of children and elderly persons (6). Some household impact studies have reported changes in dependency ratio, which was 1.2 before the death of an adult and increased to 1.4 following the death (7). The average $\mathrm{HH}$ size in this study was higher among the infected/affected $\mathrm{HH}$ compared to the controls and even higher than the national average $\mathrm{HH}$ size; this could possibly imply that the remnants of multiple infected $\mathrm{HH}$ are banding together.

It was also noted that in the four districts that the study was carried out, more than $75 \%$ of the $\mathrm{HH}$ preferred and used the public health facilities as compared to all the other facilities. However use of the Traditional Herbalists (TH) in the management of HIV/AIDS and related complications is still significant despite other prevailing conditions like availability of antiretroviral drugs. Although affordability remains a challenge, costs have reduced substantially. This phenomenon could be a coping mechanism because of costs and the fact that affected persons are willing to try anything that could offer hope of prolonging life in view of the fact that we do not yet have a definite cure for HIV/ AIDS.

\section{CONCLUSION AND RECOMMENDATIONS}

This study shows that HH expenditures on health for infected/ affected HHs are very high. Much as health services are free in public health facilities, which were reported as the most used option. There is need for government to further explore ways of subsidising health care expenses for HIV/AIDS affected HHs through improved targeting. Most of the expenses were incurred on hospitalisations, scaling up home based care for AIDS patients and equipping public health units with adequate drugs may be some of the options to reduce costs incurred by HHs.

Households coping strategies for the cost of an HIV / AIDS patient included selling of assets, use of savings and borrowing. This was worsened by loss of jobs, reduction and loss of revenue. Through the current HIV / AIDS programmes, there is need to introduce income generating activities for HIV/ AIDS affected HHs which should be sustainable if the poverty:cycle is to be broken. There is also need to develop a human rights culture or even a law to protect PLA in the society against discrimination at the work places and loss of jobs.

The AIDS pandemic has negatively affected education of the children in the affected $\mathrm{HHs}$ by not only making children attend to the sick, but also denying the children the means and opportunity to study. This will impact negatively on the work force in the future.

Significantly, it was found that most $\mathrm{HH}$ did not depend on relatives paying their medical bills as theoretically perceived by the public. This has shown that, much as the two sets of households were exposed to the same economic situations, the affected HHs were worst affected and this could therefore be attributed to HIV / AIDS. Their incomes were severely reduced yet they spend much more on health care. HIV thus remains a challenge to poverty reduction.

\section{REFERENCES}

1. Africa Development Forum; Joint United Nations Programme on HIV. 1998.

2. WHO, UNAIDS. 2000.

3. Government of Uganda; MoH/ AIDS Control Progamme, Population based Knowledge Attitude Behavior and Practice (KABP) 1997. 
4. HIV and Development programme; UNDP. 1998.

5. Government of Uganda; MoH/ AIDS Control Progamme, 2007.

6. Food and Agricultural Organization. 1997

7. Menon, R., Maria, J., Konde-Lule, J., et al. The economic impact of adult mortality on households in Rakai Districts, Uganda. In: M. Ainsworth, L. Fransen, and M. Over (Eds). Confronting AIDS: Evidence from the developing world. Selected background papers for the World Bank Policy Research Report; Confronting AIDS: Public priorities in a global epidemic. European Union and World Bank, Washington DC. 1996

8. Bollinger, L., Stover, J., Kerkhoven, R., et al. The economic impact of AIDS in Zimbabwe; Policy project, 1999.

9. Ayiga, N., James, P., Ntozi, N., et al. Causes, patterns, differentials and consequences of AIDS mortality in Northern Uganda. In: Orubuloye, Caldwell and Ntizi, L. (eds)., The continuing HIV/ AIDS epidemic in Africa: Response and coping strategies, Health Transition Centre, Australian National University, Canberra, 1999; pp. $139-154$.

10. UNAIDS Background paper for ADF, The Economic Impact of AIDS in Africa; A review of literature. 2000.

11. Adams, A., Hien, M. and Sauerborn, R. Household strategies to cope with the economic costs of illness; Social Sci. Med. 1996; 43: 291-301.

12. Rugalema, G. It is not only the loss of labour - HIV/ AIDS: Loss of household assets and household livelihood in Bukoba District, Tanzania. Paper presented at the East and Southern Africa Regional Conference on:
Responding to HIV /AIDS: Development Needs of African Smallholder, Agriculture, Harare, 8-12. 1998.

13. Bennett, S., Woods, T., Liyanage, W.M. and Smith, D.L. A simplified general method for cluster - sample surveys of health in developing countries. WHO Stat. Q. 1991; 44: 98-106.

14. Ministry of Health; AIDS Control Programme. Ante Natal Care, HIV/STD Surveillance Report, 2002.

15. Ministry of Health, AIDS Control Program; HIV / AIDS surveillance report. June 2001.

16. Barnett, T., White side, A. and Desmond, C. The social economic impact of HIV/AIDS in poor countries: A review of studies and lessons UNAIDS. 2003.

17. Desmond, C., Michael, K. and Gow, J. The hidden battle: HIV/AIDS in the family and community. Health Economics \& HIV/AIDS Research Division; University of Natal, Durban. 2000.

18. Bollinger, L. and Stover, J. Economic impact of AIDS in South Africa, Johannesburg. Futures Group International. 1999a.

19. Bechu, N. The impact of AIDS on the economy of families in Cote d'Ivoire: Changes in consumption among AIDS-affected households, in Ainsworth, Fransen and over. 2000.

20. Mutangadura, G. Household welfare impact of mortality of adult females in Zimbabwe: Implications for policy and programme development. Paper presented to the AIDS and Economic Symposium. 2000.

21. Hunter, S. Ministry of education, Kingdom of Swaziland; Sectoral assessment of the impact of HIV/ AIDS on Education. 1999. 